\title{
IMPLANTAÇÃO DO PROGRAMA DE GESTÃO E SUPERVISÃ̃O AMBIENTAL COMO ATENUANTE DOS IMPACTOS AMBIENTAIS DE UMA OBRA RODOVIÁRIA: O CASO DA BR-285/RS
}

\section{IMPLEMENTATION OF THE ENVIRONMENTAL MANAGEMENT AND SUPERVISION PROGRAM AS MITIGATION OF ENVIRONMENTAL ROAD CONSTRUCTION IMPACTS: THE BR-285/RS CASE}

\author{
Marcela Bruxel \\ Universidade Cidade de São Paulo \\ Rafael Vieira da Silva \\ UniABEU \\ Marjorie Kauffmann \\ Centro Universitário UNIVATES \\ Gustavo Kaufmann \\ Centro Universitário UNIVATES
}

\section{RESUMO}

O Programa de Gestão e Supervisão Ambiental (PGSA) executado durante a implantação de obras rodoviárias pode reduzir ou mitigar boa parte dos impactos ambientais com a utilização de métodos construtivos adequados, evitando assim danos irreversíveis ao meio ambiente, em conjunto com a busca de melhorias permanentes na qualidade ambiental. O foco deste artigo é a importância da implantação do PGSA na obra de implantação do novo traçado e da pavimentação da rodovia BR-285/RS - no trecho que liga São José dos Ausentes à Divisa RS/SC - ao atenuar os impactos ambientais provenientes da implantação desta rodovia e definir as medidas mitigadoras e compensatórias aplicáveis para minimizar tais impactos. $O$ PGSA é parte integrante do Plano Básico Ambiental (PBA) aprovado pelo IBAMA, sendo suas ações a realização do acompanhamento de todos os programas e subprogramas do PBA. Desde o início das obras, a equipe de Supervisão Ambiental realizou em período integral o gerenciamento da documentação técnica do empreendimento, o acompanhamento e atendimento das condicionantes das licenças ambientais e a fiscalização ambiental na obra, através do registro das atividades em consonância com o PBA. Em função do acompanhamento efetivo e da comunicação estabelecida com os operários, durante a obra não foram registrados impactos irreversíveis. Assim, o estudo afirma a importância da execução do PGSA, que no caso presente assegurou a continuidade do desenvolvimento da obra, tendo o acompanhamento e monitoramento por finalidade a prevenção, a mitigação e a compensação dos impactos. 
Palavras-chave: Obra Rodoviária, Programas, Subprogramas, Acompanhamento, Impactos Ambientais.

\begin{abstract}
The application of Environmental Management and Supervision Program (PGSA) duringroad constructions can reduce or mitigate most of the environmental impacts. Using appropriate construction methods is possible to avoid irreversible damage and also improve permanently the environmental quality. This study focused in the importance of PGSA implementation for the new road layout and paving at BR-285/RS highway - in the stretch connecting São José dos Ausentes City to the border of the State, specifically between RS/SC - in order to attenuate the environment impacts from this approach and define the applicable mitigating and compensatory measures to minimize such impacts.The PGSA is part of the Basic Environmental Plan (PBA) approved by IBAMA (Brazilian Institute of Environment and Renewable Natural Resources), that monitors all of the programs and subprograms of PBA. Since the beginning of the road work the Environmental Supervision Team conducted a full-time management of the project technical documentation, the monitoring and attending of licenses requirements and also the environmental supervision of the work. All of these supervision actions were registered according to the PBA orientations. During the construction work were not registered any irreversible impacts, due to the effective monitoring and the established communication within workers. So, the study supports the huge relevance of PGSA execution, which in this case assured progress of the project development having the supervision and monitoring as a prevention, mitigation and impacts compensation as caution measures.
\end{abstract}

Keywords: Road work, Programs, Subprograms, Monitoring, Environmental impacts.

\title{
INTRODUÇÃO
}

De acordo com o Departamento Nacional de Infra-Estrutura de Transportes - DNIT (BRASIL, 2006), o empreendimento rodoviário nacional está entre as realizações de maior importância para o desenvolvimento socioeconômico, trazendo acentuado poder indutor a tal desenvolvimento e se constituindo no principal elemento ou fator de integração entre as populações. No entanto, Panazollo et al. (2012) afirmam que a construção de rodovias pode apresentar inúmeros impactos sobre o meio ambiente, como desmatamentos, perda da diversidade biológica, alteração do sistema natural de drenagem e degradação do solo. Sob esta ótica, o processo de construção rodoviária deve, portanto, compatibilizar-se com a conservação ambiental a partir do uso de 
técnicas e métodos de atividades construtivas que evitem ou minimizem a degradação ambiental (PANAZOLLO et al., 2012).

Para Simonetti (2010), os impactos originados com a implantação de uma rodovia podem ser classificados como: socioeconômicos, físicos e bióticos. No meio socioeconômico, o principal impacto está relacionado às atividades econômicas da região pela rodovia transposta, pois esta facilita 0 deslocamento da população e das mercadorias, promovendo o comércio e a indústria e, com isso, ocasionando mudanças na qualidade de vida dos habitantes. No entanto, este acréscimo de trafegabilidade impacta negativamente na qualidade do ar, traz maior emissão de poluentes. No meio físico, os problemas podem ter início na fase de instalação da rodovia, que deve ser realizada de forma correta a fim de evitar instabilidades de cortes e taludes, assim como alagamentos, devido à má execução ou à obstrução das obras-de-arte especiais, o que pode acarretar processos erosivos e/ou assoreamentos dos corpos d'água próximos. No meio biótico, há uma maior incidência de atropelamentos de animais na pista, o que afeta tanto a segurança dos usuários da via quanto o afugentamento das espécies (SIMONETTI, 2010).

Lei et al. (2005), que também consideram a fragmentação de hábitat e a perda de conectividade como grandes problemas da construção de obras lineares, como as rodovias, em áreas de grande vulnerabilidade ambiental, propõem metodologias para medir esses impactos a partir da construção.

Um empreendimento rodoviário apresenta diferentes etapas até sua conclusão, sendo que também são identificados diferentes tipos e níveis de impactos ambientais. Os principais impactos decorrem das atividades de implantação e operação da rodovia, sendo que a etapa de implantação tem início na preparação do terreno material para o início da execução do projeto e se estende até o final da construção da rodovia. Nesta etapa podem ocorrer diferentes impactos decorrentes das atividades realizadas, tais como a abertura de acessos de serviço; a limpeza do terreno; a exploração de jazidas; terraplenagem; o transporte dos materiais (PANAZOLLO et al., 2012).

Fogliatti et al. (2004), consideram vários impactos ambientais negativos em todas as fases de implantação de uma rodovia, dos quais se pode destacar 
a degradação do solo durante a construção, a destruição de áreas de conservação, a poluição de águas superficiais e subterrâneas e a retenção de águas superficiais, dentre outros. Esses impactos devem ser observados no planejamento da rodovia, fazendo-se o possível para minimizá-los ou compensá-los, com a finalidade de aumentar a viabilidade ambiental do empreendimento, ou seja, diminuir o seu potencial de causar impactos ambientais negativos (FERREIRA, 2012).

Ainda de acordo com Panazollo et al. (2012), embora sejam tomadas medidas preventivas, sempre haverá impactos, sejam eles positivos ou negativos, derivados da implantação de uma rodovia; contudo, a implantação de medidas de controle e monitoramento ambiental podem reduzir ou mitigar boa parte dos impactos negativos e potencializar os positivos, medidas estas fundamentais para evitar danos irreversíveis ao meio ambiente.

Para Panta (2006), a questão ambiental deixou de ser um assunto de ambientalistas ditos "da moda" ou "de românticos", para se converter em SGA (Sistema de Gestão Ambiental) e PGA (Programa de Gestão Ambiental), que adotam normas da série ISO 14.000 (International Organization for Standartization) e outras normatizações voltadas à preservação do meio ambiente. Segundo Oliveira (2001), não se trata de um tardio despertar da consciência ecológica, mas de uma estratégia para minimizar os impactos ambientais e tornar todas as operações tão ecologicamente corretas quanto possível.

A Resolução do CONAMA $n^{\circ}$ 01/86, em seu artigo 6으, inciso IV, estabelece a elaboração de programas de acompanhamento e monitoramento dos impactos positivos e negativos, indicando os fatores e parâmetros a serem considerados.

O Plano Básico Ambiental é de fundamental importância para a implantação das medidas mitigadoras propostas no EIA/RIMA, pois a ele cabe mitigar, monitorar, controlar, compensar ou restaurar os danos ambientais que ocorrerão em função do empreendimento. Da mesma forma, são agregados às diretrizes dos planos e programas ambientais, os objetivos de potencializar benefícios ou impactos positivos das ações dos planos ambientais (BRASIL, 2012). 
A Gestão Ambiental tem por objetivo a busca permanente de melhoria da qualidade ambiental. É, portanto, um processo de aprimoramento constante do sistema de gestão ambiental global (NAVES, 2001).

O foco deste artigo é o Programa de Gestão e Supervisão Ambiental na obra de implantação do novo traçado e da pavimentação da rodovia BR285/RS, sendo que sua total conclusão propiciará um novo elo de ligação desde a fronteira oeste do Rio Grande do Sul, passando por regiões de alta produção agrícola e de turismo e abrindo uma nova opção de ligação ao resto do país através da BR-101/SC.

O objetivo deste artigo é apresentar a importância da execução do Programa de Gestão e Supervisão Ambiental no acompanhamento realizado por equipe técnica especializada na aplicação dos programas ambientais durante a obra de implantação do novo traçado e da pavimentação da rodovia BR-285/RS, como atenuante dos impactos ambientais daí provenientes e expor as medidas mitigadoras e compensatórias aplicáveis para minimização destes mesmos impactos.

\section{ÁREA DE ABRANGÊNCIA}

A área de abrangência do presente artigo trata da rodovia BR-285/RS, no trecho de $8,30 \mathrm{~km}$ compreendido entre o município de São José dos Ausentes e a Divisa RS/SC (Figuras 1 e 2).

Revista Inte

DOI: 10.1:

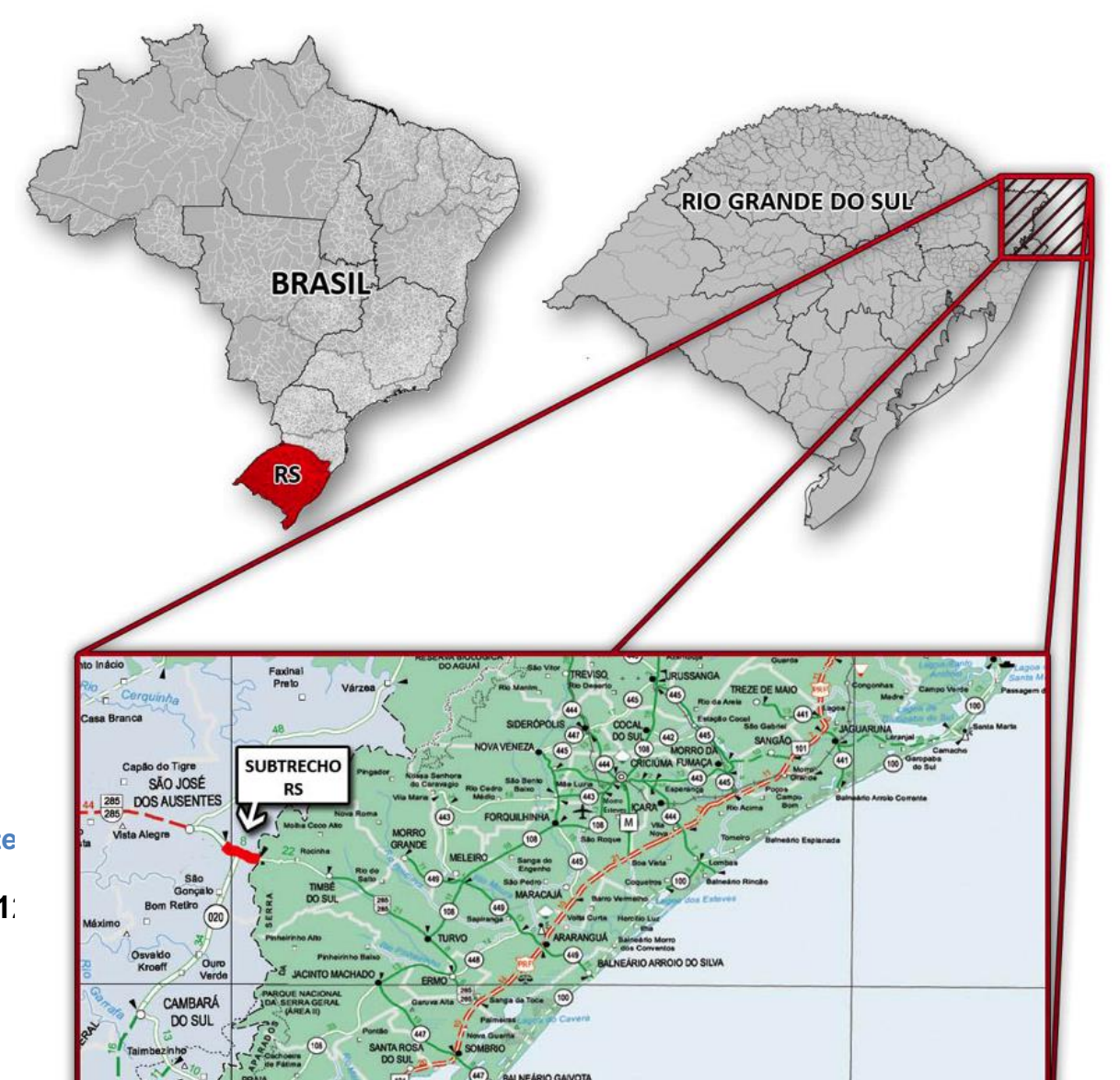


Figura 1 - Área de abrangência da BR-285/RS - Trecho entre São José dos Ausentes e a Divisa RS/SC.

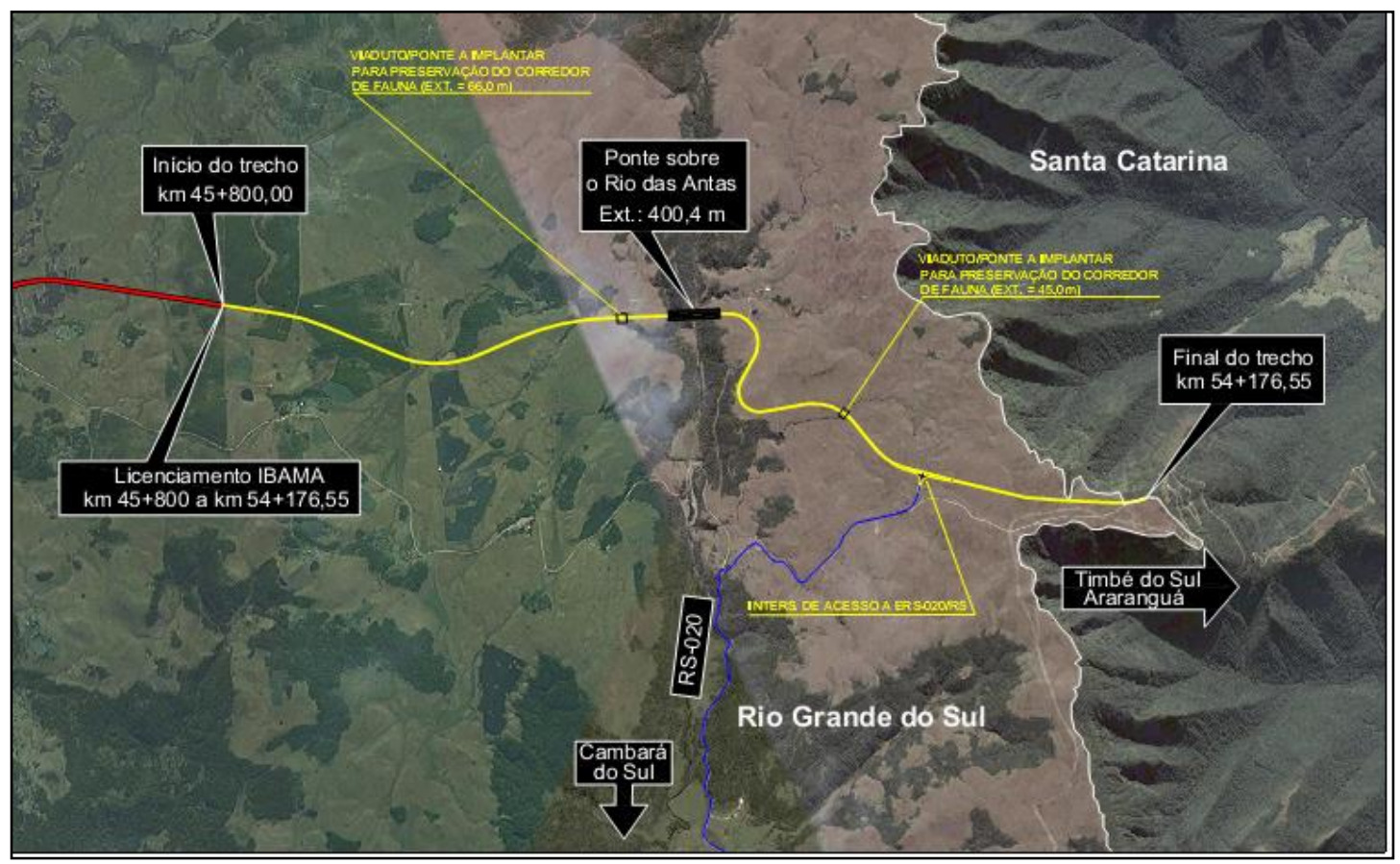

Figura 2 - Localização do traçado da BR-285/RS.

Nas obras de implantação e pavimentação da BR-285/RS, foi executado o Programa de Gestão e Supervisão Ambiental, tendo por base a Instrução de Serviço nำ 20 do Manual de Diretrizes Básicas para Elaboração de Estudos e Programas Ambientais Rodoviários do DNIT. 
O Programa de Gestão e Supervisão Ambiental (PGSA) é parte integrante do Plano Básico Ambiental elaborado pela Universidade Federal do Paraná - UFPR - no ano de 2012, com vistas à obtenção da Licença de Instalação e em atendimento ao item no 2.9 das Condições Específicas da Licença Prévia no 410/2011, emitida pelo IBAMA.

O Plano Básico Ambiental - PBA - da BR-285/RS é composto por 23 programas ambientais e 7 subprogramas (BRASIL, 2012), sendo a partir deste emitida pelo IBAMA a Licença de Instalação no 860/2012, que autoriza o início da obra mediante $\mathrm{O}$ atendimento das condições gerais e condicionantes específicas da LI, sendo que as ações do Programa de Gestão e Supervisão Ambiental preveem o acompanhamento de todos os programas $\mathrm{e}$ subprogramas do PBA.

Quadro 1 - Relação e objetivos dos Programas Ambientais do PBA

\begin{tabular}{|c|c|}
\hline Programas Ambientais & Objetivos \\
\hline Programa de Gestão e Supervisão Ambiental & $\begin{array}{l}\text { Garantir que todos os programas ambientais } \\
\text { incluídos no PBA sejam desenvolvidos e } \\
\text { aplicados conforme legislação pertinente e } \\
\text { cronograma previsto. }\end{array}$ \\
\hline Plano Ambiental da Construção & $\begin{array}{l}\text { Fornece critérios e estabelece os } \\
\text { procedimentos ambientais que devem ser } \\
\text { seguidos pela construtora, visando à } \\
\text { minimização dos danos ambientais em todas } \\
\text { as fases da construção. }\end{array}$ \\
\hline $\begin{array}{l}\text { Subprograma de Sinalização da Estrada, } \\
\text { Desvios e Acessos }\end{array}$ & $\begin{array}{l}\text { Integrante do Plano Ambiental da Construção } \\
\text { - PAC - fornece diretrizes para a construtora } \\
\text { manter a sinalização da estrada, desvios e } \\
\text { acessos nas frentes de obra, durante a fase } \\
\text { de instalação da rodovia, com o intuito de } \\
\text { evitar acidentes. }\end{array}$ \\
\hline $\begin{array}{l}\text { Subprograma de Gerenciamento de Resíduos } \\
\text { Sólidos e Efluentes }\end{array}$ & $\begin{array}{l}\text { Subprograma do PAC, fornece critérios e } \\
\text { procedimentos para a construtora destinar } \\
\text { corretamente os resíduos sólidos e efluentes } \\
\text { líquidos gerados no canteiro de obras, de } \\
\text { acordo com a legislação ambiental pertinente. }\end{array}$ \\
\hline $\begin{array}{l}\text { Programa de Controle de Ruídos, Gases e } \\
\text { Material Particulado }\end{array}$ & $\begin{array}{l}\text { Fornece medidas de controle da emissão de } \\
\text { ruídos e poeira, durante a fase de instalação } \\
\text { das obras da rodovia, de forma que não } \\
\text { prejudiquem os trabalhadores da obra nem a } \\
\text { população vizinha. }\end{array}$ \\
\hline $\begin{array}{l}\text { Programa de Monitoramento e Controle de } \\
\text { Processos Erosivos e de Contenção de } \\
\text { Instabilidades de Encostas e Taludes } \\
\text { Naturais }\end{array}$ & $\begin{array}{l}\text { Objetiva efetuar controle e até prevenção dos } \\
\text { processos erosivos decorrentes das } \\
\text { modificações no meio, provenientes das } \\
\text { ações de implantação da rodovia e das áreas } \\
\text { de seu entorno, evitando que atinjam a } \\
\text { comunidade e mantenham a integridade do } \\
\text { meio. }\end{array}$ \\
\hline $\begin{array}{l}\text { Programa de Monitoramento da Qualidade c } \\
\text { Água e Proteção de Recursos Hídricos }\end{array}$ & $\begin{array}{l}\text { Através de coleta periódica de amostras em } \\
\text { locais pre determinados, objetiva identificar as }\end{array}$ \\
\hline
\end{tabular}




\begin{tabular}{|c|c|}
\hline & $\begin{array}{l}\text { eventuais mudanças da qualidade dos corpos } \\
\text { d'água na bacia em que a obra se insere, } \\
\text { durante todo o período da construção. }\end{array}$ \\
\hline Programa de Gerenciamento de Riscos & $\begin{array}{l}\text { Cria uma estrutura de gerenciamento dos } \\
\text { riscos inerentes ao empreendimento, visando } \\
\text { minimizar os acidentes na rodovia, sendo } \\
\text { dividido em dois subprogramas. }\end{array}$ \\
\hline $\begin{array}{l}\text { Subprograma de Redução de Acidentes na } \\
\text { Fase da Implantação da Rodovia }\end{array}$ & $\begin{array}{l}\text { Prevê o adequado contingente de pessoal e } \\
\text { equipamentos necessários ao atendimento a } \\
\text { eventuais acidentes com veículos e } \\
\text { máquinas, que possam constituir uma } \\
\text { ameaça ao meio ambiente. }\end{array}$ \\
\hline $\begin{array}{l}\text { Subprograma de Transporte de Produtos } \\
\text { Perigosos }\end{array}$ & $\begin{array}{l}\text { Aplicável durante a fase de instalação e } \\
\text { operação da rodovia, tem a importância de } \\
\text { destacar mecanismos de controle para } \\
\text { prevenção de acidentes com cargas } \\
\text { perigosas que possam ameaçar o meio } \\
\text { ambiente. }\end{array}$ \\
\hline $\begin{array}{l}\text { Plano de Ação de Emergência na Fase de } \\
\text { Operação da Rodovia }\end{array}$ & $\begin{array}{l}\text { Em caso de acidente durante a operação da } \\
\text { rodovia, objetiva preservar a integridade física } \\
\text { da comunidade residente no entorno da } \\
\text { rodovia, dos usuários da mesma e do meio } \\
\text { ambiente. }\end{array}$ \\
\hline $\begin{array}{l}\text { Programa de Recuperação de Áreas } \\
\text { Degradadas e Passivos Ambientais }\end{array}$ & $\begin{array}{l}\text { Ao término das obras, é necessário um Plano } \\
\text { de Recuperação de Áreas Degradadas - } \\
\text { PRAD - para que todas as áreas que foram } \\
\text { impactadas sejam recuperadas, como o } \\
\text { canteiro de obras, central de concreto, } \\
\text { oficinas, jazidas, caminhos de serviço, } \\
\text { acessos provisórios e demais áreas externas } \\
\text { à faixa de domínio. }\end{array}$ \\
\hline $\begin{array}{l}\text { Programa de Recuperação de Passivos para } \\
\text { a Atual Estrada }\end{array}$ & $\begin{array}{l}\text { Em vista da implantação de novo traçado da } \\
\text { BR-285/RS, a estrada atual representa um } \\
\text { passivo que precisa ser recuperado após o } \\
\text { fim das obras, com intuito de não } \\
\text { potencializar os impactos negativos ao meio } \\
\text { ambiente da região. }\end{array}$ \\
\hline Programa de Recomposição Florestal & $\begin{array}{l}\text { Objetiva compensar a supressão de } \\
\text { remanescentes nativos da faixa de domínio, } \\
\text { minimizando e até corrigindo o impacto } \\
\text { ambiental sobre as comunidades e a flora } \\
\text { local. }\end{array}$ \\
\hline $\begin{array}{l}\text { Programa de Aproveitamento Científico da } \\
\text { Vegetação da Área Afetada pelo } \\
\text { Empreendimento }\end{array}$ & $\begin{array}{l}\text { Tem por objetivo o resgate de elementos } \\
\text { florísticos representativos da flora local, } \\
\text { criando uma referência científica e } \\
\text { contribuindo para o maior conhecimento da } \\
\text { região. }\end{array}$ \\
\hline Programa de Controle de Supressão Vegetal & $\begin{array}{l}\text { Define técnicas e procedimentos com intuito } \\
\text { de assegurar que a supressão vegetal } \\
\text { necessária seja executada de forma que } \\
\text { minimize os impactos ao ambiente } \\
\text { circundante. }\end{array}$ \\
\hline $\begin{array}{l}\text { Programa de Controle de Espécies Exóticas } \\
\text { Invasoras }\end{array}$ & $\begin{array}{l}\text { Objetiva controlar e evitar a dispersão de } \\
\text { espécies vegetais exóticas invasoras, que é } \\
\text { favorecida com a supressão da vegetação } \\
\text { nas áreas de obras. }\end{array}$ \\
\hline $\begin{array}{l}\text { Programa de Monitoramento da Fauna e } \\
\text { Bioindicadores }\end{array}$ & $\begin{array}{l}\text { Monitora os mamíferos, aves, peixes e } \\
\text { herpetofauna locais, permitindo maior }\end{array}$ \\
\hline
\end{tabular}




\begin{tabular}{|c|c|}
\hline & $\begin{array}{l}\text { conhecimento de importantes espécies } \\
\text { características da região, quanto a seus } \\
\text { hábitos e dinâmicas de deslocamento. }\end{array}$ \\
\hline $\begin{array}{l}\text { Programa de Controle de Atropelamentos da } \\
\text { Fauna }\end{array}$ & $\begin{array}{l}\text { Realizado durante a fase de operação da } \\
\text { rodovia, propõe mecanismos de } \\
\text { monitoramento e controle de atropelamento } \\
\text { da fauna local. }\end{array}$ \\
\hline Programa de Utilização de Mão de obra Local & $\begin{array}{l}\text { O objetivo do programa é disponibilizar o } \\
\text { adequado contingente de trabalhadores na } \\
\text { obra, priorizando a mão de obra local, para } \\
\text { que a comunidade tenha a obra como } \\
\text { referência de desenvolvimento da região. }\end{array}$ \\
\hline Programa de Comunicação Social & $\begin{array}{l}\text { Constitui-se num mecanismo facilitador da } \\
\text { condução do processo de interação entre o } \\
\text { empreendimento e a sociedade; tem por } \\
\text { objetivo informar a esta sobre a intervenção } \\
\text { que ocorrerá em seu sistema de vida. }\end{array}$ \\
\hline $\begin{array}{l}\text { Programa de Indenização, Reassentamento e } \\
\text { Desapropriação }\end{array}$ & $\begin{array}{l}\text { Visa o acompanhamento futuros dos } \\
\text { indenizados e desapropriados, garantindo } \\
\text { uma adequada compensação e inserção de } \\
\text { reassentamentos, objetivando uma melhora } \\
\text { na qualidade de vida. }\end{array}$ \\
\hline $\begin{array}{l}\text { Programa de Prevenção, Controle } \\
\text { Monitoramento de Doenças Endêmicas }\end{array}$ & $\begin{array}{l}\text { Fornece orientações, a fim de evitar a } \\
\text { disseminação de doenças endêmicas que } \\
\text { possam afetar os trabalhadores e a } \\
\text { população local. }\end{array}$ \\
\hline Programa de Educação Ambiental & $\begin{array}{l}\text { Objetiva disseminar conceitos ambientais } \\
\text { básicos à população da AID e aos } \\
\text { trabalhadores da obra, dividindo-se em dois } \\
\text { subprogramas. }\end{array}$ \\
\hline $\begin{array}{l}\text { Subprograma de Educação Ambiental nas } \\
\text { Comunidades Lindeiras }\end{array}$ & $\begin{array}{l}\text { Tem seu foco na comunidade afetada pela } \\
\text { obra, instruindo-as sobre questões ambientais } \\
\text { e incentivando a preservação do meio em que } \\
\text { está inserida. }\end{array}$ \\
\hline $\begin{array}{l}\text { Subprograma de Capacitação Funcional dos } \\
\text { Colaboradores e Terceirizados da Obra }\end{array}$ & $\begin{array}{l}\text { Voltada aos trabalhadores da obra, dissemina } \\
\text { conceitos ambientais e induz à preservação } \\
\text { do meio. }\end{array}$ \\
\hline $\begin{array}{l}\text { Programa de Fiscalização e Controle da } \\
\text { Ocupação da Faixa de Domínio }\end{array}$ & $\begin{array}{l}\text { Fiscalizar o entorno da via durante as fases } \\
\text { de instalação e operação, com intuito de } \\
\text { preservar a faixa de domínio dos invasores. }\end{array}$ \\
\hline $\begin{array}{l}\text { Programa de Controle Ambiental, caso ocorra } \\
\text { Paralisação Temporária das Obras por mais } \\
\text { de } 45 \text { dias }\end{array}$ & $\begin{array}{l}\text { Prevenir, estabilizar e, se necessário, } \\
\text { recuperar, durante eventuais períodos de } \\
\text { interrupção dos trabalhos de construção da } \\
\text { rodovia, as situações que posteriormente } \\
\text { possam se transformar em passivos } \\
\text { ambientais. }\end{array}$ \\
\hline Programa de Monitoramento Arqueológico & $\begin{array}{l}\text { Salvaguardar o patrimônio cultural e } \\
\text { arqueológico que possa ocorrer nas áreas de } \\
\text { instalação da obra, realizando o seu resgate, } \\
\text { ou até a preservação do local. }\end{array}$ \\
\hline $\begin{array}{l}\text { Subprograma de Valorização Cultural } \\
\text { Patrimônio Histórico }\end{array}$ & $\begin{array}{l}\text { Estabelece princípios de proteção ao } \\
\text { patrimônio cultural que deverão ser seguidos } \\
\text { pela construtora, obrigando-a a utilizar } \\
\text { procedimentos construtivos compatíveis com } \\
\text { a preservação do patrimônio histórico do } \\
\text { local. }\end{array}$ \\
\hline
\end{tabular}


O Plano de Gestão e Supervisão (PGSA) tem a premissa de estabelecer um sistema de acompanhamento dos aspectos ambientais gerais do empreendimento - e também dos programas ambientais formulados para redução dos impactos ambientais negativos que ocorrerão em função deste, além de estruturar a implantação das atividades ambientais sob responsabilidade do empreendedor, atendendo às recomendações dos estudos ambientais que precederam, a obtenção das atuais licenças ambientais do empreendimento e ainda viabiliza $\circ$ Gerenciamento Ambiental do Empreendimento, bem como as ações da Supervisão Ambiental e da Execução de Programas Ambientais (BRASIL, 2012).

Segundo Brasil, (2012), o PGSA possui três componentes básicos:

- Coordenação Ambiental: compreende as atividades de coordenar as ações e atividades que serão da competência do PGSA, sendo o principal canal de comunicação entre o empreendedor, os órgãos ambientais e as comunidades locais;

- Supervisão Ambiental: consiste em inspecionar todas as fases do empreendimento, garantindo que a implantação das ações/atividades prescritas estejam de acordo com as condições e especificações técnicas estabelecidas, principalmente atendendo aos programas ambientais;

- Monitoramento Ambiental: corresponde ao acompanhamento da evolução dos impactos, avaliando periodicamente seus efeitos/resultados e propondo - quando necessário - alterações, complementações e/ou novas ações ambientais.

A implantação do PGSA está diretamente relacionada com a execução de todos os programas ambientais; portanto, o período de implantação deste programa se dá integralmente na fase de instalação das obras e na fase de operação (BRASIL, 2012).

Para a execução do PGSA, é composta uma equipe técnica multidisciplinar de profissionais qualificados, exigida no acompanhamento da regularidade ambiental do empreendimento, visto que o PGSA envolve todos os programas ambientais do PBA (BRASIL, 2012).

\section{RESULTADOS}


As obras de implantação da rodovia BR-285/RS foram iniciadas pelo DNIT em 26/11/2012, com a Supervisão Ambiental a cargo da Consultora Enecon S/A, composta por técnicos com experiência na gestão ambiental em rodovias.

A equipe de Supervisão Ambiental realizou em período integral o gerenciamento da documentação técnica do empreendimento, abrangendo o acompanhamento e atendimento das condicionantes das licenças ambientais, as autorizações e portarias, além da participação em reuniões e vistorias técnicas e da fiscalização ambiental na obra, através do registro das atividades em consonância com o PBA, estabelecendo sempre a comunicação com a equipe técnica da construtora e do DNIT.

Do total dos 23 programas ambientais e 7 subprogramas do PBA, foram aplicados 16 programas e 5 subprogramas, listados abaixo, estes sem registro de inconformidades e impactos ambientais negativos:

- Programa de Gestão e Supervisão Ambiental

- Plano Ambiental da Construção

- Subprograma de Sinalização da Estrada, Desvios e Acessos

- Subprograma de Gerenciamento de Resíduos Sólidos e Efluentes

- Programa de Controle de Ruídos, Gases e Material Particulado

- Programa de Monitoramento e Controle de Processos Erosivos e de Contenção de Instabilidades de Encostas e Taludes Naturais

- Programa de Monitoramento da Qualidade da Água e Proteção de Recursos Hídricos

- Programa de Recuperação de Áreas Degradadas e Passivos Ambientais

- Programa de Controle de Supressão Vegetal

- Programa de Aproveitamento Científico da Vegetação da Área Afetada pelo Empreendimento

- Programa de Monitoramento da Fauna e Bioindicadores

- Programa de Utilização de Mão de obra Local

- Programa de Comunicação Social

- Programa de Prevenção, Controle e Monitoramento de Doenças Endêmicas 
- Programa de Educação Ambiental

- Subprograma de Educação Ambiental nas Comunidades Lindeiras

- Subprograma de Capacitação Funcional dos Colaboradores e Terceirizados da Obra

- Programa de Fiscalização e Controle da Ocupação da Faixa de Domínio

- Programa de Monitoramento Arqueológico

- Subprograma de Valorização Cultural e Patrimônio Histórico

- Programa de Controle Ambiental, caso ocorra Paralisação Temporária das Obras por mais de 45 dias

Em função de alguns programas ambientais estarem relacionados à operação da rodovia, não foi efetuada a aplicação, bem como a de outros não executados por questões burocráticas, resultando em 7 programas ambientais e 2 subprogramas sem aplicação.

\section{CONCLUSÕES}

A comunicação estabelecida entre a equipe técnica da supervisão ambiental com os operários da obra foi essencial, pois através do detalhamento dos procedimentos de trabalho da equipe ambiental e de orientações para a execução adequada dos serviços - utilizando como base os conhecimentos e experiências dos operários - favoreceu-se em muito os trabalhos de execução da obra. Com efeito, a constatação imediata de problemas/impactos e suas respectivas correção e mitigação evitaram desta forma, a ocorrência de impactos irreversíveis e o registro de inconformidades ambientais.

Em função do acompanhamento eficaz e da comunicação estabelecida durante a obra, não foram registrados impactos irreversíveis, sendo que o de maior monta efetivamente desencadeado foi aquele relacionado aos taludes e às drenagens, devidamente revertidos no decorrer da obra.

O estudo afirma a importância da execução do Programa de Gestão e Supervisão Ambiental que, no caso da implantação da rodovia BR-285/RS, assegurou a continuidade do desenvolvimento da obra, tendo 0 acompanhamento e o monitoramento da obra por finalidades a prevenção, a mitigação e compensação dos impactos. 


\section{REFERÊNCIAS}

BRASIL. Departamento Nacional de Infraestrutura de Transportes. Diretoria de Planejamento e Pesquisa. Coordenação Geral de Estudos e Pesquisa. Instituto de Pesquisas Rodoviárias. Manual para Atividades Ambientais Rodoviárias. Rio de Janeiro, 437 p. (IPR. Publ. 730), 2006.

. Resolução do CONAMA no 01, de 23 de janeiro de 1986. Dispõe sobre os critérios básicos e diretrizes gerais para avaliação de impacto ambiental. Diário Oficial da República Federativa do Brasil, Brasília, DF, p. 2548-2549, 17 fev de 1986.

. Universidade Federal do Paraná. Plano Básico Ambiental das Obras de Implantação da BR-285/RS. Trecho São José dos Ausentes/RS - Divisa $\mathrm{RS} / \mathrm{SC}-8,30 \mathrm{~km}$. Instituto Tecnológico de Transportes e Infraestrutura. Curitiba, 2012.

. Departamento Nacional de Infraestrutura de Transportes. Relatórios Semestrais no 01 ao 06 dos Serviços de Supervisão e Gestão Ambiental da BR-285/RS. Enecon S.A. Porto Alegre/RS, 2013/2014/2015.

ENECON S.A. Relatórios Mensais de Supervisão/Gestão Ambiental da BR285/RS no 01 ao 31. Porto Alegre, 2013/2014/2015.

FERREIRA, V. G. A. Viabilidade Ambiental de traçados rodoviários: o caso do trecho sul do Rodoanel Mário Covas, São Paulo. Dissertação de Mestrado, Escola de Engenharia São Carlos - USP, São Carlos/SP, 2012.

FOGLIATTI, M. C., et al. Avaliação de Impactos Ambientais - Aplicação aos Sistemas de Transporte. Rio de Janeiro: Interciência, 2004.

LEI, W.; QIAOFU, Z; SHUANGCHENG, L. Road construction and landscape fragmentation in China. Journal os Geographical Sciences. V. 15, p, 123-128, 2005.

NAVES, F. L.; et al. Introdução ao estudo de gestão e manejo ambiental. Lavras: Gráfica Universitária/UFLA, 2001. 
OLIVEIRA, Marcelo S. de. ISO 14.000. Lavras: Gráfica Universitária/UFLA, 2001.

PANAZOLLO, A. P.; FRANTZ, L. C.; AURÉLIO, S. O. S.; COSTA, F. L.; MUÑOZ, C. Gestão ambiental na construção de rodovias. O caso da BR-448 Rodovia do Parque. $3^{\circ}$ Congresso Internacional de Tecnologias para o Meio Ambiente. Bento Gonçalves-RS, Brasil, 2012.

PANTA, V. M. Municipalização dos Sistemas de Licenciamento Ambiental: Estudos de caso na região do Vale do Rio Pardo - RS. Dissertação de Mestrado, UNISC, Santa Cruz do Sul, 2006.

SIMONETTI, H. Estudo de Impactos Ambientais Gerados pelas Rodovias: Sistematização do Processo de Elaboração do EIA/RIMA. Universidade Federal do Rio Grande do Sul, Porto Alegre, 2010.

UFPR. Instituto Tecnológico de Transportes e Infraestrutura. Estudo de Impacto Ambiental e Relatório de Impacto Ambiental nas Obras de Implantação e Pavimentação da Rodovia BR-285/RS, trecho São José dos Ausentes/RS a Timbé do Sul/SC. Volumes I, II, III, IV, V e VI. Curitiba, 2011. 